\title{
A revision of the generic limit between Clitocybe and Lepista
}

\author{
Harri Harmaja \\ Botanical Museum, University of Helsinki, SF-00170 Helsinki, Finland
}

\begin{abstract}
Harmaja, H. 1974: A revision of the generic limit between Clitocybe and Lepista. Karstenia 14: 82-92. - On the basis of various spore characters, some already noted but partly neglected (e.g. cyanophilic spore wall) and some $\gg n e w »$, it is concluded that Lepista (Fr.) W. G. Smith (Agaricales) is a valid genus, and independent of Clitocybe (Fr.) Staude. The current concept of Lepista is, however, somewhat altered, since the genus is considered to include species with smooth (under the light microcope) and deep yellow spores. The inclusion of the Clitocybe gilva group in Lepista is also considered justified. The essential characters of the amended genus Lepista are given, of which the strongly cyanophilic spore wall and the presence of a remarkable proportion of collapsed spores are emphasized. It seems that the type of Lepista, viz. Agaricus lepista Fr., can probably be appropriately typified, so that for the fungi concerned the generic name Lepista is thus indeed correct and available. Some other nomenclatural remarks are also made. Two new combinations are made in Lepista, the species in question having previously been referred to Clitocybe (the first of these even being one of the most famous species of that genus): Lepista nebularis (Fr.) Harmaja and Lepista subalpina (Big. \& Smith) Harmaja.
\end{abstract}

\section{Introduction}

Recently Bigelow and A. H. Smith (1969) amalgamated the agaric genus Lepista (Fr.) W. G. Smith 1870 (= Rhodopaxillus Maire 1913) with Clitocybe (Fr.) Staude 1857 as a new section, Clitocybe sect. Verruculosae Big. \& Smith. They unfortunately fail to give the author citation of Clitocybe, but this treatment must indicate that they, too, approve Staude instead of Kummer as the author who elevated the Friesian tribe to the generic status, since if KUMMER with his 1871 paper were preferred, the generic name $L e$ pista would have priority of one year over Clitocybe sensu Bigelow \& Smith. Anyway, the name of their new section is illegitimate, being superfluous, as they include in it $\mathrm{Le}$ pista nuda, which is the type of Rhodopaxillus sect. Genuinae Konr. \& Maubl. 1924-
1937, if, in agreement with Singer (1962), that sectional name is considered to have been validly published. The classical differences, much emphasized by SinGER (e.g. 1962), between Clitocybe and Lepista lie in the spores. In the former genus they are said to be white, yellow or pale pinkish in mass, and normally smooth; if they are not smooth, then they are supposed to be always white in print. In Lepista the spores should be pale pinkish in deposit, and always more or less roughened. BigELow and Smith (1969) considered these classical features and concluded that there is no difference of generic degree between the Clitocybe and Lepista species. Some Clitocybe species have spores which, though white (some of these observations on colour may be vitiated by too thin a deposit) are rough with an ornamentation similar to that found 
in Lepista, while some have spores which, though smooth, are pale pinkish as in Lepista. They also pointed to the existence of Lepista species with extremely low warts on their spores. Their conclusion is further supported by the fact that in Lepista (at least in L. irina) the same gills may produce smooth (under the light microscope) spores besides distinctly rough ones, and these authors even claim that there exists in the Lepista group a species (C. pseudoirina Big. \& Smith) with only smooth spores, in which delicate verrucae are visible only in electron micrographs.

Indeed, if the combination of pale pinkish spore colour and a roughened spore wall were in fact the only thing separating Lepista from Clitocybe, the amalgamation performed by these American authors would be understandable. Like Bigelow and Sмiтh, I was dissatisfied with the common practice of separating the Clitocybe gilva group generically from the Lepista species (HaRmaja 1969), but I was unwilling to accept their solution to this problem. Instead, I suggested that this group should be included in Lepista, irrespective of the colour of the spores in the species of this group (which, anyway, was always pinkish in those specimens I studied).

I am now even more convinced that $L e$ pista, with some amendments, is a valid genus, and thus take quite the opposite view to that of Bigelow and SMith, even though the classical differences do not always apply in the distinction between Lepista and Clitocybe. The reason is that during my continued studies in and around Clitocybe I observed two obviously diagnostic characters for separating these genera, neither of which have been mentioned by the two American authors (Bigelow \& Smith 1969). The present contribution also includes some other taxonomical and nomenclatural notes as well as some neglected observations from the literature.

Acknowledgements. - I am indebted to Dr. Robert L. Shaffer (MICH) for placing certain specimens at my disposal. I am also grateful to Mr. Mauri Korhonen for taking the photographs.

\section{The characters separating Lepista from Clitocybe}

Immediately after the publication of my paper on the Fennoscandian Clitocybes (Harmaja 1969), I began to use the heated cotton blue techniques (see Kotlaba \& PouZAR 1964) in Agaricales taxonomy, a method with which I became acquainted during studies on Discomycetes. Among many other interesting things, I observed that in the »classical» species of Lepista (sensu SiNGER 1962) studied by me, the spore wall (or some of its outer layers), including the warts, is strongly cyanophilic. In very young spores it is still cyanophobic but it soon begins to absorb the dye, the mature and old spores staining darkest blue. The wall in the hilar appendix seems, however, to be cyanophobic (unless very weakly cyanophilic?). The species studied were: L. irina, L. luscina, L. nuda, L. rickenii, L. sordida, C. subalpina Big. \& Smith (which will be formally transferred to Lepista later in this paper), L. subconnexa, and several others which were impossible to identify. Subsequently it was found that the cyanophilic spore wall of Lepista was by no means unknown in the literature, since LAMOURe \& Fichet (1962) remark, as a mere detail, that the spore wall of a Lepista species they call »Rhodopaxillus densifolius Favre» stains intensely in »Bleu lactique» (= cotton blue). KüHNER (1969) found the spore wall of L. irina to be cyanophilic, Besson (1970), another member of the skilful French school, mentioned that the same applies to the spore wall and its ornamentation in L. irina and L. luscina (called L. panaeola), and finally Singer (1972) made the same observation as regards $L$. ameliae, $L$. argentina, $L$. densifolia, L. irina, L. nuda, L. sordida and $L$. subconnexa.

The other character which seems to possess great diagnostic value is that a considerable proportion of Lepista spores (especially the immature ones still attached to the sterigmata) constantly have strikingly shrunken, or collapsed walls, being almost or completely without contents. I have so far mostly made this observation on water, Melzer, and cotton blue squash mounts, made of the lamellae of dried basidiocarps, but occasional observations on the spores of deposits also revealed the presence of collapsed spores. Strangely enough, it appears that the literature does not mention this striking phenomenon, apart from my report on L. subconnexa (Harmaja 1970). The 
reason for this collapse is uncertain. One explanation which suggests itself is that these shrunken spores are unripe and for some genetically determined reason have unusually soft walls, which become irreversibly collapsed in drying, especially as they are more or less devoid of contents (due to their immature stage?). Or, possibly the walls are shrunken at first in the normal fresh condition, and swell out as the spores receive their plasm (and nuclei?) and become turgid.

It subsequently appeared reasonable to check Clitocybe species for these two characters, to see whether they might provide a distinction between Lepista and Clitocybe at the generic level. I already considered the C. gilva group to belong to Lepista, in view of its distinctly warted and thickish-walled spores, which are pinkish-tinted in deposit (at least in the various »forms» studied by me) (Harmaja 1969), and this group did indeed reveal a strongly cyanophilic spore wall and ornamentation as well as a conspicuous proportion of collapsed spores. The cyanophilic spore wall in this group had, however, already been reported in the literature, e.g. by Kühner (1969), Besson (1970), and Singer (1972). In addition, at high magnifications under the electron microscope, the spore ornamentation in C. gilva coll. is seen to be very similar to that present in Lepista (Bigelow \& Rowley 1968). These facts should be final justification of the opinion held by a small number of workers on agarics that $C$. gilva coll. is congeneric with the classical species of Lepista. In his paper mentioned just above, Singer (1972) has changed his previous opinion and come to the same conclusion.

It may be mentioned here that the taxonomy of the L. gilva group is in urgent need of revision, and that, to my knowledge, no satisfactory solution has yet been suggested. We may have here just one very variable species, or two or three, or more. According to my observations, attention should be paid to at least the following points: the colours of the fruit body, the hygrophanity of the pileus, the pileus surface when dry (whether distinctly concentrically wrinkled or not), the thickness of the context (also at the pileus margin), the exact colour of the spore deposit, the exact size and shape of the spores (whether subglobose or more or less broadly ellipsoid), the kind of spore base, the length and distribution of the verrucae of the spores, and of course the ecological and distributional features. For the present, I recommend that the name used for this group should be »Lepista gilva (Fr.) Roze coll.», because the existing original material is of Agaricus gilvus Pers. ex Fr., consisting of one specimen in the Persoon herbarium in Leyden, studied by Singer (1961) and by me. Sometimes PatouILLARD is cited as the author who transferred the species to Lepista but Roze's (1876: 110) combination has priority.

A great many other species ascribed to Clitocybe and several undescribed ones were studied. It turned out that (with one important exception to be treated below in the third section) their spore wall is either completely cyanophobic or only weakly cyanophilic, never being collapsed in notable amounts of spores (Fig. 1 a). (It should be mentioned here that a careful distinction should always be made between the spore wall and spore contents, since the latter are usually more or less cyanophilic.)

Thus it seems that we have attained a delimitation of Lepista which is more natural than earlier ones, and at the same time found characters which truly justify according $L e-$ pista the rank of genus, and which also give a fairly convenient routine method for telling whether a single specimen belongs to Clitocybe or Lepista.

\section{Relationship of Clitocybe nebularis to Lepista}

The species of Clitocybe that forms the exception mentioned above in section 2, possessing both a strongly cyanophilic spore wall and a very striking proportion of shrunken spores (Fig. $1 \mathrm{~b}$ ), is C. nebularis (Fr.) Kumm. I want to emphasize that, according to my studies, all the 21 other species included by me (Harmaja 1969) in the type subgenus of Clitocybe had completely cyanophobic spore walls, including those fleshy species previously always supposed to be closely related to $C$. nebularis. (All but one of the 11 species of the sections $L a$ tisporae, Ditopae and Strigipedes of the subgenus Pseudolyophyllum also proved to have cyanophobic spore walls, while those of the subgenus Roseospora and the type section of the subgenus Pseudolyophyllum as well as $C$. schulmannii of the section Strigipedes, 11 altogether, possess weakly cyanophilic spore walls). Singer (1972) also mentions that some species of Clitocybe have cyanophobic spore walls, while others possess cyanophilic ones. He included C. nebularis among the latter species, but observed that the cyanophilic 

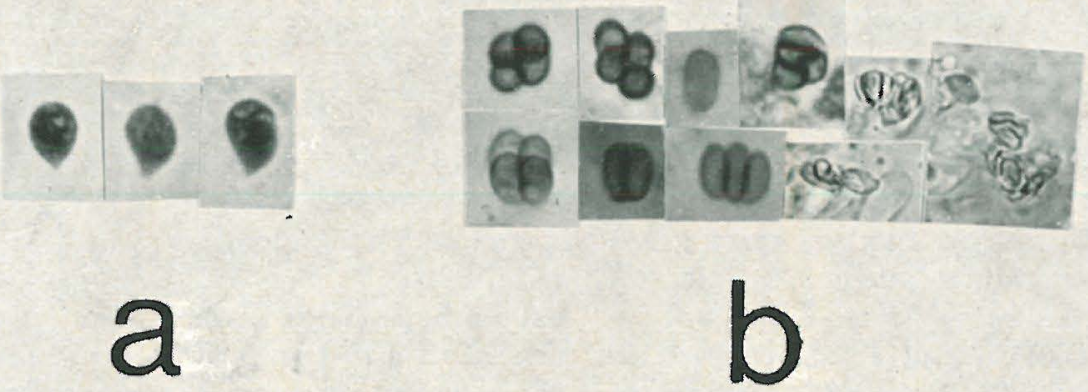

Fig. 1. Spores in heated cotton blue squash mount, prepared from dried gills. Bright field, $\mathrm{x} 1000$. Photo by M. Korhonen. - a) Clitocybe gibba (Fr.) Kumm., the type species of Clitocybe (Finland, Etelä-Häme, Hattula, 25. IX. 1967, H. Harmaja; H). Note the lacrymoid shape and the thick confluent base of the spores, which drift about singly in the mountant and possess normal and very thin walls. The spores are equally dark throughout (except for some paler oil drops) as their contents are weakly to moderately cyanophilic while the very thin walls are cyanophobic and not discernible. - b) Lepista nebularis (Fr.) Harmaja (Finland, VarsinaisSuomi, Lohja, 2. XI. 1967, H. Harmaja; H). Note the principally ellipsoid shape of the obtuse-based spores, which, besides occurring singly, are also commonly seen in tetrads and dyads (very rarely even three adhered together), a part of them, including those immature ones still attached to the sterigmata, having collapsed walls and no contents (three of the four groups on the right representing such spores have been photographed in Melzer's reagent with a lower magnification). The spore walls are thickened and cyanophilic, the borders of the spores being seen to be darker than their contents. Some of the spore clusters are seen from above.

character in this species is weaker than in the others, in contrast to my results. (Anyway, Singer does not use my procedure of recognizing three categories of matter on the basis of its capacity to absorb the dye: (1) weakly cyanophilic, (2) moderately cyanophilic and (3) strongly cyanophilic matter.) Even in an earlier study (Harmaja 1969), $C$. nebularis was found to possess certain characters which were unique in Clitocybe (a good proportion of spores collapsed; spore deposit deep yellow; different parts of dried fruit body unusually rich in chlorine tinges under ultra-violet light), and which led me to place it in a different section from the other fleshy species! As, besides the two very important characters dealt with above, the other features of $C$. nebularis (see below) also seem to suggest a relationship with $L e$ pista, or at least do not exclude this possibility, this species should be transferred to $L e-$ pista, although its spores are smooth (at least under the light microscope) and lack a pinkish colour.

The habit of $C$. nebularis is distinctly clitocyboid, the lamellae usually being completely decurrent, but in the classical Lepistas there is a well-known tendency for the gills, mostly more or less adnate-sinuate, to be decurrent, and in L. subconnexa at least they are clearly decurrent (Bigelow \& Smith 1969; Harmaja 1970). Moreover, since the publication of my paper on the Fennoscandian Clitocybes, I have found fruit bodies of $C$. nebularis with many of the gills somewhat sinuate near the stipe. An even more important find was my discovery in southern Finland, in the Lohja limestone district, of a curious fungus, which was whitish and possessed a non-hygrophanous pileus and almost Tricholoma-like, sinuate, not even slightly decurrent lamellae. When fresh this agaric possessed an odour of $C$. nebularis, not being so fragrant as L. irina, and gave the impression of a Lepista rather than that of a Tricholoma. I was very eager to see what its spores looked like, and my surprise was great when they turned out to be completely smooth under the light microscope and almost identical with those of $C$. nebularis (the size of the hilar appendix is slightly different), possessing all the features treated above. Clamp connections were abundant. A spore deposit was unfortunately not obtained. According to current taxonomy, this species would have keyed out 
among the clamped Tricholomas! This fungus should of course be included in Lepista, together with $C$. nebularis, being in a way a connecting link between the bulk of Lepista and $C$. nebularis, as it possesses a Lepista habitus but is microscopically extremely close to $C$. nebularis. This species, L. singeri Harmaja (Harmaja 1974), may help to solve the problem of the »smooth-spored Lepista irina» of some authors, which others often place in Tricholoma. A new subgenus of Lepista, based on $C$. nebularis and $L$. singeri, will be established (Harmaja 1974). Generally, macroscopic characters, such as the attachment of the gills to the stipe and the presence versus absence of a stipe, or the position of the latter, should be used very carefully in the generic taxonomy, and only in connection with other, preferably microscopic, features.

As regards the reactions of $C$. nebularis under ultra-violet light, a typical member of Lepista, L. subconnexa, was observed by me to display a similar and even more conspicuous chlorine colour in different parts of its dried fruit body, and this feature might also be considered evidence of the relationship of $C$. nebularis to Lepista. BigeLow and SмIтн (1969) report that L. subconnexa (as Clitocybe s.) and C. phyllophila appear to be close to each other in all characters but the spore surface. However, I consider a close relationship unlikely, not only because there are several differences in their spores (e.g., the spore wall in $C$. phyllophila is smooth and only weakly cyanophilic), but because their ultra-violet responses also differ. Dried basidiocarps of these species may indeed sometimes seem very alike, but they are easily distinguished from each other without the aid of a microscope. For instance, under ultra-violet light, with a wave length of 254 $\mathrm{nm}$, the pileus of $L$. subconnexa is luminously chlorine coloured, while that of $C$. phyllophila remains mat and pale, with some violet tinges.

The deep yellow spore colour present in C. nebularis is unknown in Lepista in its current concept, but I think that it can be considered to lie within the amplitude of variation in spore colour of this genus, where different shades of reddish colour are already known (see e.g. Bigelow \& SMith 1969). The important point is that the spore print is distinctly coloured in sufficiently thick de- posits in both the bulk of Lepista and in $C$. nebularis.

The smooth spores of $C$. nebularis may at first sight seem to exclude it from Lepista. But here I agree with Bigelow and Smith (1969: 165), who write about the »futility of trying to use arbitrarily a character such as spore ornamentation to separate 'natural groups'». The important point is that the Lepista species and $C$. nebularis evidently have a homological layer in their spore wall, viz. the strongly cyanophilic one, which generally develops projections, ranging from very small to fairly coarse ones. It should be remembered that even now the smoothspored $C$. nebularis and L. gilva coll. with verruculose spores are almost uniformly considered congeneric, but both referred to Clitocybe! It would not be surprising if the spore wall of $C$. nebularis turned out to be uneven under the electron microscope. L. irina may be considered a species intermediate between the bulk of Lepista on the one hand and $C$. nebularis and $L$. singeri on the other, as a part of the spores of L. irina seem to be smooth under the light microscope, while the rest of them possess low warts. Moreover, it should be pointed out that the spores in Lepista and C. nebularis also seem to be very similar in several respects other than the most important ones already mentioned. The spore wall in $C$. nebularis is somewhat thickened, my latest studies showing it to be ca. $0.3-0.4 \mu \mathrm{m}$ thick (in contrast to my earlier opinion), and this feature also suggests relationship with Lepista. In addition the spore shape, the often depressed suprahilar area of the spores, and the spore contents with a distinct oil drop or drops accord completely with the characters of Lepista.

Also, the odour, taste and edibility as well as the ecological and distributional characters of $C$. nebularis accord very well with the characters of Lepista.

In an earlier paper (HARMaja 1969), I agreed with those who preferred to typify the genus Clitocybe with $C$. nebularis. Now I must change my opinion and support those considering $C$. gibba the lectotype. A most inconvenient situation would arise if my taxonomical conclusions were accepted and at the same time $C$. nebularis were regarded as the type. For instance, the name Clitocybe would replace Lepista 
and a very great number of new combinations would be necessary, so that the general principle of stabilizing the nomenclature would not be followed. As $C$. gibba is also the type of the section Infundibuliformes (Fr.) Sing. \& Dig. of Clitocybe, this well-known sectional name must inevitably be considered a synonym of the name of the type section, sect. Clitocybe.

4. The occurrence of spores adhering together in tetrads and the taxonomical significance of this character

One more interesting but neglected feature of Lepista spores is that in all the species studied a certain amount of the spores (including the collapsed ones) can be seen to adhere together in tetrads and dyads, e.g. in water, $\mathrm{KOH}(5 \%)$, Melzer's reagent and heated cotton blue, when the mount was prepared from a piece of dried lamella. The proportion of adhering spores in all the detached spores drifting in the mountant may be rather small or even more than 50 per cent, varying with the species. There does not seem to be any earlier mention of this character in the literature, apart from my observation concerning L. subconnexa (Harmaja 1970). In the present case this feature is not of great diagnostic value at the generic level (but evidently has significance at the infrageneric and suprageneric levels), since it is present in different groups of Clitocybe (Harmaja 1969); and, conversely, the occurrence of spores adhering together in fours and twos is almost negligible in L. gilva coll. In this respect, too, the spores of $C$. nebularis are typical of Lepista, the majority of them being stuck together in this way (HARMAJA 1969) (Fig. 1b).

In my paper on the Fennoscandian Clitocybes cited above I perhaps did not make it sufficiently clear that the possible occurrence of spore tetrads and dyads should be studied in squash mounts made from a piece of dried lamella.

My earlier tentative explanation of this phenomenon was subsequently disproved by microscopic studies of fresh, drying lamellae of two species with single spores (C. gibba and Agrocybe cf. dura) and one with tetrads $(C$. odora). The lamellae were lying free on an object glass, and I found that, as the tissue dried and lost its turgidity, the sterigmata supporting the unripe spores at their tips began to collapse and turned towards each other. Accordingly in all three species the spores, when viewed from above, were seen to come nearer and nearer to each other, until they finally touched and formed a cluster of four spores. When completely dry, these same fragments of lamellae were squashed in Melzer's reagent and the mount was observed; two different cases were seen: the spores of the Agrocybe species and those of $C$. gibba loosened readily from the sterigmata and also from each other, drifting about singly in the mounting liquid, while the detached spores of $C$. odora mostly occurred in fours and twos, as was of course expected (Harmaja 1969). Thus this peculiar character observed in a major or minor part of the spores of certain species is perhaps explained in the following way. When the unripe spores on the sterigmata of these species come into contact with each other as described above, their undeveloped walls or some outer layer(s) of these are gelatinized and sticky, and thus the four spores not only touch but cling together as if glued, continuing to do so even when the gill tissue is crushed during the preparation of microscopic slides. The occurrence of spore dyads can easily be explained by the cleavage of tetrads and/ or the presence of occasional two-spored basidia among the normal four-spored ones.

A different situation presumably prevails in most of the Basidiomycetes, where, although »spore tetrads», as viewed from above, may be seen in intact dried lamellae, the spore walls are evidently not sticky, and the spores are readily separated when the basidia are crushed or shaken during the preparation of microscopic mounts. There may also be species with rigid walls in the sterigmata, in which case the latter with their unripe spores may not approach each other when drying.

I have observed spore tetrads in the species of many other genera besides $\mathrm{Cli}$ tocybe and Lepista, e.g. Collybia, Lepiota, Lyophyllum, Pseudoclitocybe and Rhodocybe, and I selieve that this character, which has proved very useful in Clitocybe (Harmaja 1969), may also be found to 
possess diagnostic value at different taxonomic levels outside that genus.

\section{The essential characters of the amended genus Lepista}

Lepista (Fr.) W. G. Smith is thus amended to comprise species with the following characteristics (compare Fig. 1b): fruit bodies medium-sized to large, with a tricholomoid to clitocyboid habit, and very variable colours; pileus hygrophanous or not; basidia without siderophilous granulation, with inamyloid, indextrinoid and cyanophobic walls; spore print lightly coloured, either pinkish or deep yellow; spores uninucleate (KüHNER 1945); a major to minor proportion of the spores (especially the immature ones?) stick together in tetrads and dyads, at least in water, $\mathrm{KOH}(5 \%)$, Melzer and cotton blue mounts of dried gills; a good proportion of the spores (especially the immature ones) conspicuously collapsed in water, Melzer and cotton blue mounts (at least in mounts of dried gills; also in all those cases when deposits were studied); spore base invariably obtuse (unless acute in a small proportion of the spores of $L$. gilva coll.?); spore shape very ordinary, being ellipsoid or ellipsoidoblong, rarely subglobose; suprahilar area of the spores very often depressed, if not, then applanated, being smooth under the light microscope in rough spore walls also, but often (if not always?) centrally slightly rugose under the electron microscope (BIGELOW \& Rowley 1968; Pegler \& Young 1971); spore wall somewhat thickened, inamyloid and indextrinoid, strongly cyanophilic except in very young spores, in which cyanophobic, usually verruculose with obtuse warts often increasing in number and size towards the spore apex, rarely smooth under the light microscope; hilar appendix distinct, rather small, with cyanophobic (or very weakly cyanophilic?) walls; spore contents almost always with one more or less distinct oil drop; cystidia of any kind absent; hymenophoral trama regular or nearly so; cortex of pileus rather poorly differentiated, composed of thin filamentous hyphae; all hyphae with inamyloid and indextrinoid, probably also cyanophobic walls; clamp connections abundant in all parts of the fruit body; on bare soil and in litter, often where the ground is rich in nutrients, usually not in wet habitats or on wood, evidently not forming ectotrophic mycorrhiza; distribution cosmopolitan in very variable climatic conditions.

\section{The relationship of Lepista to certain genera}

My preliminary studies suggest that other features besides the classical differences distinguish Tricholoma and Collybia from Lepista. The two genera, sometimes confused with or supposed to be related to Lepista, evidently as a rule have a cyanophobic spore wall, and their spores are generally not conspicuously collapsed and mostly (at least in Tricholoma) do not occur in tetrads or dyads. Singer (1972) also reports the spores of those species of Collybia and Tricholoma studied by him to possess cyanophobic walls (except in some very occasional spores in $T$. saponaceum; see later).

However, in certain species of Tricholoma (e.g. T. caligatum, $T$. inamoenum, $T$. saponaceum, $T$. sejunctum, $T$. sulphureum) and Collybia (so far only in the species of the Rhodocollybia group: $C$. maculata, $C$. distorta and $C$. butyracea) I have observed most curious scattered, finally sometimes secondarily septate basidia, with thick, strongly cyanophilic walls throughout, constantly occurring among normal basidia and producing spores of more or less normal size and shape (except for those of $C$. butyracea at a final stage; see below) but similarly thick-walled and strongly cyanophilic. (In addition, in $C$. butyracea narrow belts with the same colour reactions occur around the septa of some pileus hyphae.) Gertain details of these basidia are different in different species. This phenomenon is, however, not connected with the cyanophily of the Lepista spore, since these elements occur along with the normal ones, and are also strongly dextrinoid, unlike any cell in $\mathrm{Le}$ pista. I have never seen such structures in Clitocybe, either.

This very peculiar situation in Tricholoma and Collybia has to my knowledge not been reported before in the literature not excepting a recent paper on Tricholoma (Gulden 1969). However, Singer (1962) does write that in Tricholoma a few dextrinoid spores may very infrequently be 
found among the normal indextrinoid ones, and in his 1972 paper he reports that a thin cyanophilic outer layer is present in the wall of a few spores of $T$. saponaceum. However, he fails to observe the conspicuous aberrant basidia. It is very interesting to note that Singer \& Clémençon (1971) have found exactly similar basidia in Aeruginospora hiemalis, calling them »sclerobasidia».

Unexpectedly, spore characters have been reported as normal in the aphyllophorous genus Jaapia Bres. (see NANNFELDT \& ERIKSSON 1953: Fig. 1, h-l) that are extremely similar to those present in, e.g., the aberrant spores of C. butyracea, viz. the apparent double structure of the wall (evidently also present in the aberrant basidia in Tricholoma and Collybia), the occurrence of septa within old detached spores and the common collapsing of the small basal cell, and the response to cotton blue (and also the dextrinoid reaction, according to my own observations on the two Jaapia species).

The phenomenon may be connected with a curious type of chlamydospore formation. Another possible explanation is that it is caused by some parasite (Archimycetes?), which has developed in the basidia and spores of the host species, inside the thin, cyanophobic, inamyloid and indextrinoid basidial and sporal walls. The genera Rhodocybe, Rhodophyllus, Clitopilus and their relatives do not appear to be very closely related to Lepista (or Clito$c y b e$ ). Firstly, they have binucleate spores (KüHNER 1945), further they usually seem to have a thicker spore wall and a deeper reddish colour in their spore deposits. The two last-mentioned features accord with my observation that, when viewed under the microscope, in water, $\mathrm{KOH}$, or even Melzer's reagent, even single spores of many of the species of these genera clearly have reddish-tinted walls, while in Lepista (and Clito$c y b e$ ) the reddish tinge is hardly observable in single spores, even if they are pale pinkish in deposit. In addition, in these genera the walls of very young spores attached to the sterigmata are already generally more or less strongly cyanophilic, while they may in some species become less so with age, so that in certain species at least a small proportion of the completely mature spores possibly even have cyanophobic walls (according to $\mathrm{KüH}-$ NER 1969 and my own studies). In Lepista (and certain Clitocybes) the opposite is true, since the spore wall is always cyanophobic in very young spores, its ability to absorb cotton blue increasing with age. Lastly, clamp connections are commonly absent from these genera with binucleate spores, while they never seem to be lacking in Lepista (and only very infrequently in Clitocybe).

The genus Ripartites has clamps and distinctly coloured, uninucleate (KüHNER 1945) spores possessing verruculose, strongly cyanophilic walls (KüHNer 1969; Besson 1970; Singer 1972; my own studies), and, according to my observations, a small proportion of its spores are adhered together in tetrads in preparations made of dried gills. It is thus clearly very close to Lepista taxonomically, as has already been pointed out, e.g. by SinGER (1962), KüHNER (1969) and Besson (1970), being to my mind particularly near to the L. gilva group. As described by SinGER (1962) however, Ripartites differs sufficiently from Lepista to deserve recognition as an independent genus. I have also found that in Ripartites the proportion of collapsed spores is smaller than in Lepista.

In the comparisons of Lepista with other genera, Clitocybe included, I have not regarded as decisive the two classical features whose combination has hitherto generally been supposed to be diagnostic of Lepista, i.e. the pinkish spore colour and the verruculose spore wall. This of course results from my attempts to obtain a more natural delimitation of the genus, in which the amplitude of variation of the spore characters also covers a deep yellow spore colour and a smooth spore wall as seen under the light microscope. The pinkish verruculose spores of Lepista of course still form an average difference from, say, Clitocybe. However, my most recent observations, to be published on a later occasion, show that, besides the wellknown occurrence of pinkish coloured spores in Clitocybe, the genus also contains a few species with slightly rough spores (cf. also the spore wall of C. atrostriata Métr.). Moreover, Pegler and Young (1971) report the spore surface of $C$. clavipes to be rugulose under the electron microscope (this observation, by the way, confirms my 1969 opinion that this species deserves a section of its own; it would not be surprising if the 
spores of the evidently closely related species C. avellaneialba Murr. also revealed a slightly rugose wall when studied under the electron microscope). C. pseudoirina Big. \& Smith (type Smith 71356; MICH) is considered by Bigelow \& SMith (1969) to occupy an intermediate position between Lepista and Clitocybe as regards its spore ornamentation (see p. 83). The authors claimed that its spores were smooth under the light microscope, even when studied with an oil immersion lens, but, on examining the type and only specimen, I can tell that in reality a large proportion are distinctly rough as in the true L. irina, appearing so not only when stained with cotton blue, but also in Melzer's reagent, and even at as low a magnification as $x 600$. Thus the classical diagnostic features of $C$. pseudoirina (pinkish spore colour; at least many of the spores verruculose) indicate that it should be placed in Lepista, giving no support to the idea that it is an intermediate species. This is confirmed by my further studies on the type, which showed that a part of the spores occur in tetrads, that a proportion of them are collapsed, and that the spore wall is strongly cyanophilic. Moreover, all the characters of $C$. pseudoirina, both macroscopic and microscopic, strongly suggest that it is conspecific with $L$. irina. The other species thought by Bigelow and Smith to have an intermediate kind of spore surface, $C$. highlandensis Hesl. \& Smith, lacks clamp connections, and, as admitted by these authors, is thus not a particularly suitable example to choose in this case. The connections of this at least superficially curious species to Rhodocybe, Tricholoma and the $C$. harperi group should be checked by a careful analysis of its spore characters.

\section{The basionym and typification of Lepista}

The basionym of the generic name Lepista is practically invariably considered to be »Paxillus tribus Le pista Fr.» (FrIEs: Epicrisis, 1838), subsequently elevated to the generic status by W. G. Smith (Clavis Agaricinorum, 1870). The name of FrIES is, however, not validly published as he misplaced the tribe through treating it as an infrageneric taxon (International Code of Botanical Nomenclature, 1972, Art. 33). The only exception to this rule is the treatment of the tribes of FrIEs as subdivisions of genera in »Systema
Mycologicum» (»Code», Art. 33). The »Epicrisis» is, however, a later work quite different from that starting point publication, nor is it nomenclaturally considered a part of the »Systema Mycologicum» according to the »Code» (unlike FrIEs's »Elenchus fungorum», 1828). Thus the above tribe of FrIes cannot serve as the basionym for new combinations, from which it follows that the proposed new combination Lepista (Fr. 1838) W. G. Smith 1870 is not validly published, either. However, fortunately this problem can be solved with practically no alterations to the current taxonomy or nomenclature of Lepista. Somewhat later (Summa vegetabilium Scandinaviae 2: 306, 1849) Fries treats the Lepista group immediately under the generic name Paxillus as an infrageneric taxon whose rank he fails to indicate: »Paxillus a. Lepista». The characters of this group »a.» are described in a few words and three species are included: $\gg 1$. P. Lepista [in italics] / 2. P. extenuatus (Scop.) / 3. P. sordarius (Pers.)», none of them being, however, designated as the type. This taxon without a designation of rank is the first supraspecific taxon, validly published in all respects, which can be typified with Agaricus lepista Fr., and, although Fries of course means by it the same group of fungi as in the $\gg$ Epicrisis» under the same Latin epithet, Paxillus a. Lepista must be treated as a new taxon and not as a mere new combination because the name was not validly published in the »Epicrisis». It is this taxon »a. Lepista» of Paxillus that may validly be given a new status. To be exact, the complete citation of the name of that taxon should be $\gg$ Paxillus a. Lepista Fr. ex Fr.», but the first citation $\gg$ Fr.» and the word »ex» are of course not necessary in routine use. Donk (1962) interprets the taxon »a.» as section, but that procedure does not seem correct since in the work considered FrIEs used this kind of letters $(a, b, c$, etc.) to denote stirpes in those infrequent cases when he made any mention of the rank (e.g. in the first subgenus of Agaricus, subg. Amanita). The stirps is, however, not an official rank approved by the »Code», and moreover, FrIES used the word »stirps» and those small letters rather inconsistently. The word »section» is even more rarely found in the work, denoting even less any distinctly defined taxonomical position. W. G. Sмiтh is thus to be considered 
to have made the new combination Lepista (Fr. 1838 ex Fr. 1849) W. G. Smith 1870. Donk (1962) seems to have been aware of the facts mentioned above, but, apparently because he failed to present any detailed explanations and emphasize the correct form of the basionym, they escaped the attention of subsequent workers.

As the epithet of the subdivision of the genus Paxillus, the taxon Paxillus a. Lepista, is »identical with [or derived from] the epithet of one of its constituent species, this species [Paxillus lepista] is the type of the name of the subdivision of the genus unless the original author of that name designated another type» (»Code», Art. 22). Thus the »selection of a lectotype» for Lepista, according to Donk (1962) first made by W. G. Smith in 1908 in favour of P. lepista, is superfluous.

The identity of Agaricus lepista Fr. (Paxillus lepista (Fr.) Fr.; the author citation is mostly given incorrectly as P. lepista Fr., though this species was originally described in the »Systema Mycologicum» under the generic name $A$ garicus) has been the subject of some discussion. To me the original description (as well as the later ones of FRIES) of this species, with notes on its macroscopic features and the colour of its spores, strongly suggests some species in fact belonging to Lepista, especially L. subconnexa (Murr.) Harmaja (or some very closely related species). L. subconnexa has been shown to occur in Norway and Finland, i.e., on both sides of Sweden (Harmaja 1970), so it is most probable that it also grows in Sweden, where it may have been collected by FrIEs and been in his hands when he was preparing the original description of Agaricus lepista. L. subconnexa may be a collective species, but at least one specimen collected in southern Finland (Etelä-Häme prov., Lammi, Biological Station 1968-07-02, Pertti Uotila; H) is conspecific with the North American type as it possesses large cespitose fruit bodies and was growing on rich bare soil, or mull.

\section{The formal proposals of two new combinations}

Lepista nebularis (Fr.) Harmaja, n. comb. (Agaricus nebularis Batsch ex Fries, Systema mycologicum ... 1: 86. 1821.)

Lepista subalpina (Big. \& Smith) Harmaja, n. comb. (Clitocybe subalpina Bigelow \& Smith, Brittonia 21: 155. 1969. — Part of holotype [MICH] studied.)

\section{REFERENCES}

Besson, M. 1970: Ultrastructure de la paroi sporique de quelques Agaricales à ornements cyanophiles non amyloïdes. - C. R. Acad. Sci. 271: D: 1508-1510 + I-II

Bigelow, H. E. and Rowley, J. R. 1968: Surface replicas of the spores of fleshy fungi. Mycologia 60: 869-887.

Bigelow, H. E. \& Smith, A. H. 1969: The status of Lepista - a new section of Clitocybe. Brittonia 21: 144-177.

Donk, M. A. 1962: The generic names proposed for Agaricaceae. - Beih. Nova Hedwigia 5: $1-320$.

Gulden, G. 1969: Musseronflora. Slekten Tricholoma (Fr. ex Fr.) Kummer sensu lato. $96+4$. Oslo, Bergen \& Tromsø.

Harmaja, H. 1969: The genus Clitocybe (Agaricales) in Fennoscandia. - Karstenia 10:5168.

- 1970: Type studies on Agaricales described as Clitocybe and Omphalina. - Karstenia 11: $35-40$.

- 1974: Three new taxa of Lepista: L. fasciculata n. sp., L. singeri n. sp. and Lepista subgenus Laevispora n. subg. - Karstenia 14: $129-132$.

Kotlaba, F. and Pouzar, Z. 1964: Preliminary results on the staining of spores and other structures of Homobasidiomycetes in cotton blue and its importance for taxonomy. Feddes Repert. 69: 131-142.

KüHNER, R. 1945: Nouvelles recherches sur les divisions nucléaires dans la baside et les spores des Agaricales. - G. R. Acad. Sci. 220: $618-620$.

- 1969: Contribution à la systematique des Orcelles (Agaricales). Cette tribu est-elle artificielle comme le suggèrent des particularités de la paroi sporique en microscopie photonique? - Bull. Soc. Linn. Lyon 38: $247-251$.

Lamoure, D. et Fichet, M.-L. 1962: Rhodopaxillus densifolius Favre, espèce nouvelle pour la France. - Bull. Soc. Linn. Lyon 31:107111.

NAnnfeldt, J. A. and Eriksson, J. 1953: On the hymenomycetous genus Jaapia Bres. and its taxonomical position. - Svensk Bot. Tidskr. 47: $177-189$

Pegler, D. N. and Young, T. W. K. 1971: Basidiospore morphology in the Agaricales. Beih. Nova Hedwigia 35: $1-210+1-$ 53.

Roze, E. 1876: Catalogue des Agaricinées observées aux environs de Paris. - Bull. Soc Bot. France 23: 108-115. 
Singer, R. 1961: Type studies on Basidiomycetes. X. - Persoonia 2: $1-62$.

- 1962: The Agaricales in modern taxonomy. - 2nd ed. - $915+$ 73. Weinheim.

- 1972: Cyanophilous spore walls in the Aga- ricales and agaricoid Basidiomycetes. Mycologia 64: 822-829.

Singer, R. und Glémençon, H. 1971: Neue Arten von Agaricales. - Schweizerische Zeitschr. Pilzk. 49: $118-128$. 